International Journal of Computer Networks \& Communications (IJCNC) Vol.5, No.1, January 2013

\title{
EFFECT OF DUTY CYCLE ON ENERGY CONSUMPTION IN WIRELESS SENSOR NETWORKS
}

\author{
Jyoti Saraswat $^{1}$, and Partha Pratim Bhattacharya ${ }^{2}$ \\ Department of Electronics and Communication Engineering \\ Faculty of Engineering and Technology \\ Mody Institute of Technology \& Science (Deemed University) \\ Lakshmangarh, Dist. Sikar, Rajasthan, \\ Pin - 332311, India. \\ ${ }^{1}$ jyotisaraswat.mitegmail.com \\ ${ }^{2}$ hereispartha@gmail. com
}

\begin{abstract}
Most studies define a common duty cycle value throughout the wireless sensor networks (WSNs) to achieve synchronization among the nodes. On the other hand, a few studies proposed adaptation of the duty cycle according to uniform traffic conditions to decrease the energy consumption and latency. In this paper, the lifetime of the nodes based on overall energy consumption are estimated and the effect of duty cycle on expected energy consumption is studied. The proposed scheme is compared with a standard scheme and is shown to perform significantly better for sufficient node density.
\end{abstract}

\section{KEYWORDS}

Wireless sensor network, Sensor nodes, Battery lifetime, Energy efficiency, Power management strategies, Low power listening, Node density, Lifetime prediction

\section{INTRODUCTION}

The multi functional sensor nodes that are small in size and communicate unbounded in short distances have been developed due to the recent advances in microelectronic fabrication and wireless communication technologies. Wireless sensor networks [1] consist of a large amount of small sensor nodes. These small sensors have the ability of data processing, sensing and communicating with each other and to the outside world through the external base station. These sensor nodes are widely used in residential, medical, commercial, industrial, and military applications [2]. Wireless sensor network devices have limited energy to complete large tasks. So, one of the challenging issues in wireless sensor networks is designing an energy efficient network.

Sensor node is a microelectronic device which can only be equipped with a limited power source [3]. Many techniques have been proposed in recent years for estimating and enhancing battery lifetime [4]. A variety of strategies is used to exploit battery characteristics for designing more "battery friendly" systems and communication. To maximize the operating life of battery-powered systems such as sensor nodes, it is important to discharge the battery in such a way so that it maximizes the amount of charge extracted from it [5]. Optimal resource management is an important challenge for maximizing the battery operation lifetime and its

DOI : $10.5121 /$ ijenc.2013.5109

125 
success requires methodical modeling of the factors contributing to the overall power consumption. Therefore, it is necessary to study the discharge rate of battery taking into consideration the battery type, capacity, discharge pattern and other physical parameters. Many researchers have proved that the only way a node can save substantial energy is to power off the radio, since transmitting, receiving and listening to an idle channel are functions which require roughly the same amount of power. One of the basic and most commonly used power management techniques is Duty Cycling. Duty cycling is a technique where a node is periodically placed into the sleep mode which is an effective method of reducing energy dissipation in wireless sensor networks (WSNs).

The traffic load in typical wireless sensor networks is relatively low ( 0.01 to 10 packets/second) and packets are relatively short (less than 500 bits). The nodes spend most of their time idle for monitoring the channels. By introducing heavy duty cycling in each node the advantage of low activity rate can be taken. In duty cycled operation [6], a node follows a sleep-wake up-samplecompute-communicate cycle in which majority of the cycle spend their time in low power sleep state. As the duty cycle increases, the nodes can sleep longer and more energy will be saved, whereas few of the nodes are available to participate in data routing, which will decrease the throughput and increase transmission latency. To reduce the duty cycle, we should decrease the active time of the node as much as possible taking into account some limitations. Duty-cycled does not require continuous sampling or communication which makes its operation possible in WSNs.

The rest of the paper is organized as follows: we briefly described related work in Section 2 . Our proposed model is presented in Section 3. Results and discussion are reported in Section 4 followed by conclusion in Section 5.

\section{RELATED WORKS}

Energy is a very sparse resource for sensor systems and has to be managed sensibly in order to extend the life of the sensor nodes. Many works have been done to reduce the power consumption and lifetime of wireless sensor networks. In general two main enabling techniques are identified i.e. duty cycling and data- driven approaches. Duty cycling [6] is the most effective energy-conserving operation in which whenever the communication is not required, the radio transceiver is placed in the sleep mode.

To increase the energy efficiency of the sensor nodes many related works have been done. Honghai Zhang et. al [7] derived an algorithm based on the derived upper bound, an algorithm that sub optimally schedules node activities to maximize the $\alpha$-lifetime of a sensor network. In [7], the node locations and two upper bounds of the $\alpha$-lifetime are allocated. Based on the derived upper bound, an algorithm that sub optimally schedules node activities to maximize the $\alpha$-lifetime of a sensor network is designed. Simulation results show that the proposed algorithm achieves around $90 \%$ of the derived upper bound. MS Pawar et. al [8] discussed the effect on lifetime, and energy consumption during listen (with different data packet size), transmission, idle and sleep states. The energy consumption of WSN node is measured in different operational states, e.g., idle, sleep, listen and transmit. These results are used to calculate the WSN node lifetime with variable duty cycle for sleep time. They concluded that sleep current is an important parameter to predict the life time of WSN node. Almost $79.84 \%$ to $83.86 \%$ of total energy is consumed in sleep state. Reduction of WSN node sleep state current $\mathrm{I}_{\text {sleep }}$ from $64 \mu \mathrm{A}$ to $9 \mu \mathrm{A}$ has shown improvement in lifetime by 193 days for the $3.3 \mathrm{~V}, 130 \mathrm{mAh}$ 
battery. It is also analyzed that the WSN node lifetime also depends on the packet size of data. Data packet size is inversely proportional to the life time of the node. As data packet size is increased, the lifetime of the battery is decreased. Yuqun Zhang et. al [9] proposed an adaptation method for the derived distance-based duty cycle which is based on local observed traffic. In this paper, the Packet Delivery Ratio (PDR) values are achieved by three methods. According to their simulation, in all the three methods the PDR results are very close and higher than $97 \%$ for light traffic loads. With an increase in traffic load, the constant duty cycle method performs the best because its higher duty cycle can provide more awake nodes to participate in data routing. The slightly worse performance of TDDCA (Traffic- Adaptive Distance-based Duty Cycle Assignment) compared to the constant duty cycle method indicates that the fixed increments and decrements in duty cycle is not efficient in terms of PDR. TDDCA and DDCA (Distance-based Duty Cycle Assignment) are more energy-efficient than the constant duty cycle method, and that DDCA performs better than TDDCA. DDCA reduces energy dissipation between $21 \%$ and $32 \%$ compared to the constant duty cycle method, while TDDCA reduces energy dissipation between $12 \%$ and 19\% compared to the constant duty cycle method. Muralidhar Medidi and Yuanyuan Zhou [10] provided a differential duty cycle approach that is designed based on energy consumed by both traffic and idle listening. It assigns different duty cycles for nodes at different distances from the base station to address the energy hole problem, improve network lifetime, and also to maintain network performance. In [11], Francesco Zorzi et. al analyzed the impact of node density on the energy consumption in transmission, reception and idle-listening in a network where nodes follow a duty cycle scheme. They considered the energy performance of the network for different scenarios, where a different number of nodes and different values of the duty cycle are taken into account. In [12], Joseph Polastre et. al proposed B-MAC i.e. a carrier sense media access protocol for wireless sensor networks, that provides a flexible interface to obtain ultra low power operation, high channel utilization and effective collision avoidance. B-MAC employs an adaptive preamble sampling scheme to reduce duty cycle and minimize idle listening to achieve low power operation. They compared B-MAC to conventional 802.11- inspired protocols, specifically S-MAC. B-MAC's flexibility results in improved packet delivery rates, latency, throughput, and energy consumption than S-MAC.

\section{Proposed Model}

In this proposed model, the lifetime of the node based on overall energy consumption is evaluated. The total energy consumption of the nodes consists of the energy consumed by listening, receiving, transmitting, sampling data and sleeping. Effect of duty cycle on the energy consumed by the nodes is also evaluated, based on the observations the optimum value of the duty cycle can be chosen. The proposed model is compared with a standard protocol STEM (Sparse Topology and Energy Management). STEM provides a way to establish communications in the presence of sleeping nodes. Each sleeping node wakes up periodically to listen. If a node wants to establish communications, it starts sending out beacons polling a specific user. Within a bounded time, the polled node will wake up and receive the poll, after which the two nodes are able to communicate. An interesting feature of STEM is that a dual radio setup is envisioned, with separate frequencies used for wakeup and actual data transmission. Our proposed model performs significantly better than STEM. 
International Journal of Computer Networks \& Communications (IJCNC) Vol.5, No.1, January 2013

\subsection{Evaluation of Lifetime of the Node Based on Overall Energy Consumption}

The lifetime of the nodes is evaluated by the overall energy consumption of the nodes such as in [12]. If the energy consumption decreases, then the lifetime of the nodes is increased. The total energy concumed by the nodes consists of the energy consumed for receiving $\left(E_{\mathrm{rx}}\right)$, transmitting $\left(E_{t x}\right)$, listening for messages on the radio channel $\left(E_{\text {listen }}\right)$, sampling data $\left(E_{d}\right)$ and sleeping $\left(\mathrm{E}_{\text {sleep }}\right)$. The notations and values listed in Table 1 and Table 2 are used throughout the paper. Total energy consumed is given by

$$
E=E_{r x}+E_{t x}+E_{\text {listen }}+E_{d}+E_{\text {sleep }}
$$

The energy associated with sampling data $E_{d}$, is

where, $\quad \begin{aligned} E_{d} & =t_{d} C_{\text {data }} V \\ t_{d} & =t_{\text {data }} \times r\end{aligned}$

$t_{d}$ being the time of sampling data, $t_{\text {data }}$ is the sample sensors, $r$ is the sample rate (packets/s), $\mathrm{C}_{\mathrm{data}}$ is the current of sample sensors $(\mathrm{mA}), \mathrm{V}$ is the voltage.

The energy consumed by transmitting $\left(\mathrm{E}_{\mathrm{tx}}\right)$ is the length of the packet with the preamble times the packets rates,

$$
\mathrm{E}_{\mathrm{tx}}=\mathrm{t}_{\mathrm{tx}} \mathrm{C}_{\mathrm{txb}} \mathrm{V}
$$

where,

$$
t_{t x}=r \times\left(L_{\text {preamble }}+L_{\text {packet }}\right) t_{\text {txb }}
$$

$\mathrm{t}_{\mathrm{tx}}$ is the time to switch the transmitter, $\mathrm{L}_{\text {preamble }}$ is the preamble length (bytes), $\mathrm{L}_{\text {packet }}$ is the packet length (bytes), $\mathrm{t}_{\mathrm{txb}}$ is the time ( $\mathrm{s}$ ) to transmit 1 byte, $\mathrm{C}_{\mathrm{txb}}$ is the current required to transmit 1 byte, $\mathrm{V}$ is the supply voltage.

The density of neighbors surrounding a node is referred to as the neighborhood size of the node. Receiving data from neighbors shortens a node's lifetime. The total energy consumed by receiving data $\left(\mathrm{E}_{\mathrm{rx}}\right)$ is given by

$$
\mathrm{E}_{\mathrm{rx}}=\mathrm{t}_{\mathrm{rx}} \mathrm{C}_{\mathrm{rxb}} \mathrm{V}
$$

where,

$$
\mathrm{t}_{\mathrm{rx}} \leq \mathrm{nr}\left(\mathrm{L}_{\text {preamble }}+\mathrm{L}_{\text {packet }}\right) \mathrm{t}_{\mathrm{rxb}}
$$

$t_{r x}$ is the time (s) to switch the receiver, $n$ is the neighborhood size of the node, $t_{r x b}$ is the time (s) to receive 1 byte data, $\mathrm{C}_{\mathrm{rxb}}$ is the current required to receive 1 byte data.

Table 1.Time and current consumption parameters

\begin{tabular}{|c|c|c|c|c|}
\hline Operation & \multicolumn{2}{|c|}{ Time $(\mathrm{s})$} & \multicolumn{2}{c|}{$\mathrm{I}(\mathrm{mA})$} \\
\hline Initialize radio(b) & $350 \mathrm{E}-6$ & $\mathrm{t}_{\text {rinit }}$ & 6 & $\mathrm{c}_{\text {rinit }}$ \\
\hline Turn on radio (c) & $1.5 \mathrm{E}-3$ & $\mathrm{t}_{\text {ron }}$ & 1 & $\mathrm{c}_{\mathrm{ron}}$ \\
\hline Switch to RX/TX (d) & $250 \mathrm{E}-6$ & $\mathrm{t}_{\mathrm{rx} / \mathrm{tx}}$ & 15 & $\mathrm{c}_{\mathrm{rx} / \mathrm{tx}}$ \\
\hline Time to sample radio (e) & $350 \mathrm{E}-6$ & $\mathrm{t}_{\mathrm{sr}}$ & 15 & $\mathrm{c}_{\mathrm{sr}}$ \\
\hline
\end{tabular}


International Journal of Computer Networks \& Communications (IJCNC) Vol.5, No.1, January 2013

\begin{tabular}{|c|c|c|c|c|}
\hline Evaluate radio sample (f) & $100 \mathrm{E}-6$ & $\mathrm{t}_{\mathrm{ev}}$ & 6 & $\mathrm{c}_{\mathrm{ev}}$ \\
\hline Receive 1 byte & $416 \mathrm{E}-6$ & $\mathrm{t}_{\mathrm{rxb}}$ & 15 & $\mathrm{c}_{\mathrm{rxb}}$ \\
\hline Transmit 1 byte & $416 \mathrm{E}-6$ & $\mathrm{t}_{\mathrm{txb}}$ & 20 & $\mathrm{c}_{\mathrm{txb}}$ \\
\hline Sample sensors & 1.1 & $\mathrm{t}_{\text {data }}$ & 20 & $\mathrm{c}_{\text {data }}$ \\
\hline
\end{tabular}

Table 2. Parameters used in Calculations

\begin{tabular}{|c|c|c|}
\hline Notation & Parameter & Default \\
\hline $\mathrm{C}_{\text {sleep }}$ & Sleep Current $(\mathrm{mA})$ & 0.030 \\
\hline $\mathrm{C}_{\text {batt }}$ & Capacity of battery $(\mathrm{mAh})$ & 2500 \\
\hline $\mathrm{V}$ & Voltage & 3 \\
\hline $\mathrm{L}_{\text {preamble }}$ & Preamble Length (bytes) & 271 \\
\hline $\mathrm{L}_{\text {packet }}$ & Packet Length (bytes) & 36 \\
\hline $\mathrm{t}_{\mathrm{i}}$ & Radio Sampling Interval $(\mathrm{s})$ & $100 \mathrm{E}-3$ \\
\hline $\mathrm{R}$ & Sample Rate (packets/s) & $1 / 300$ \\
\hline $\mathrm{L}$ & Expected Lifetime $(\mathrm{s})$ & - \\
\hline
\end{tabular}

In order to reliably receive packets, the low power listening (LPL) check interval, $\mathrm{t}_{\mathrm{i}}$, must be less than the time of the preamble,

$$
\mathrm{L}_{\text {preamble }} \geq\left[\mathrm{t}_{\mathrm{i}} / \mathrm{t}_{\mathrm{rxb}}\right]
$$

The power consumption of a single LPL radio sample is considered as $17.3 \mu \mathrm{J}$ [12]. The total energy spent listening to the channel is the energy of a single channel sample times the channel sampling frequency.

$$
\begin{gathered}
\mathrm{E}_{\text {sample }}=17.3 \mu \mathrm{J} \\
\mathrm{t}_{\text {listen }}=\left(\mathrm{t}_{\text {rinit }}+\mathrm{t}_{\text {ron }}+\mathrm{t}_{\mathrm{rx} / \mathrm{tx}}+\mathrm{t}_{\mathrm{sr}}\right) \times \frac{1}{\mathrm{t}_{\mathrm{i}}} \\
\mathrm{E}_{\text {listen }} \leq \mathrm{E}_{\text {sample }} \times \frac{1}{\mathrm{t}_{\mathrm{i}}}
\end{gathered}
$$

where, $t_{\text {rinit }}$ is the initialize radio time, $t_{r o n}$ is the turn in radio time, $t_{r x / t x}$ is switch to $r x / t x$ time, $t_{s r}$ is the time to sample radio.

The node must sleep for the rest of the time, so the sleep time $t_{\text {sleep }}$, is given by

$$
\begin{aligned}
& \mathrm{t}_{\text {sleep }}=1-\mathrm{t}_{\mathrm{rx}}-\mathrm{t}_{\mathrm{tx}}-\mathrm{t}_{\mathrm{d}}-\mathrm{t}_{\text {listen }} \\
& \text { and } \mathrm{E}_{\text {sleep }}=\mathrm{t}_{\text {sleep }} \mathrm{C}_{\text {sleep }} \mathrm{V}
\end{aligned}
$$

The lifetime of the node (L) depends on the capacity of the battery $\left(\mathrm{C}_{\text {batt }}\right)$ and the total energy consumed by the battery (E) and given by

$$
\mathrm{L}=\frac{\mathrm{C}_{\mathrm{batt}} \times \mathrm{V}}{\mathrm{E}}
$$


The lifetime of the node is also depended on the duty cycle (d) and the transmission energy $\left(E_{\mathrm{tx}}\right)$, as the duty cycle increases the lifetime of the battery decreases. Lifetime (in seconds) may be given as

$$
\mathrm{L}=\frac{\left(\mathrm{C}_{\mathrm{batt}} \times 3600\right)}{\left(\mathrm{E}_{\mathrm{tx}} \times \mathrm{d}\right)}
$$

\subsection{Effect of Duty Cycle on Expected Energy Consumption}

The traffic relayed at a node is related to its distance to the sink, the packet traffic generated by each source node, the number of source nodes in the network and the node density. The time required for a transmission and the energy efficiency of the network is closely related to the duty cycle values used. Higher values of duty cycle provide more nodes available for data routing and thereby energy consumption of the nodes increases.

In [9], a circle area is assumed with the sink located in the center and the nodes including the sources which are uniformly randomly allocated as illustrated in Figure 1, where $r_{T}$ is the transmission range. The $n$th ring is defined as the ring whose inner circle is $(n-1) r_{T}$ away from the sink with width $\mathrm{r}_{\mathrm{T}}$.

$\mathrm{N}_{\mathrm{n}}$ nodes are considered in this ring. The average traffic that must be relayed by all of the nodes located in the nth ring per unit time, $\Gamma_{\mathrm{n}}$, is the summation of the traffic generated by the source nodes in the nth ring and within the rings outside of the nth ring per unit time, i.e.,

$$
\Gamma_{\mathrm{n}}=\lambda_{\mathrm{g}} \rho_{\mathrm{s}} \pi\left(\mathrm{R}^{2}-\left[(\mathrm{n}-1) \mathrm{r}_{\mathrm{T}}\right]^{2}\right)
$$

where, $\lambda_{\mathrm{g}}$ is the average traffic generation rate of the source nodes, $\rho_{\mathrm{s}}$ is the density of source node, $\mathrm{R}$ is the radius of the network area, $\mathrm{r}_{\mathrm{T}}$ is the transmission range.

The traffic relayed at a node is depended on the node distance from the sink, the node density, the radius of the network area, and the transmission range. The average traffic rate of a node at distance $r, \lambda_{r}$, is

$$
\lambda_{\mathrm{r}}=\frac{\lambda_{\mathrm{g}} \rho_{\mathrm{s}} \pi\left\{\mathrm{R}^{2}-\left[\left(\left[\frac{\mathrm{r}}{\mathrm{r}_{\mathrm{T}}}\right]-1\right) \mathrm{r}_{\mathrm{T}}\right]^{2}\right\}}{\rho_{\mathrm{r}} \pi\left\{\left[\left(\left[\frac{\mathrm{r}}{\mathrm{r}_{\mathrm{T}}}\right]\right) \mathrm{r}_{\mathrm{T}}\right]^{2}-\left[\left(\left[\frac{\mathrm{r}}{\mathrm{r}_{\mathrm{T}}}\right]-1\right) \mathrm{r}_{\mathrm{T}}\right]^{2}\right\}}
$$

The relay region [13] (locations with geographic advancement to the sink) is divided into $\mathrm{N}_{\mathrm{p}}$ priority regions, and each region is assigned a contention slot such that priority region $\mathrm{i}$ is assigned the ith slot in the contention window. We assign each priority region $\mathrm{N}_{\mathrm{r}}$ [9] CTS contention slots, such that priority region $i$ is assigned the $\operatorname{slots}\left(\left(\mathrm{N}_{\mathrm{i}}-1\right) \times \mathrm{N}_{\mathrm{r}}, \mathrm{N}_{\mathrm{i}} \times \mathrm{N}_{\mathrm{r}}-1\right)$. This reduces CTS collisions, as all nodes in priority region i can select one of the $\mathrm{N}_{\mathrm{r}} \mathrm{CTS}$ contention slots to send their CTS packet.

The following analysis of the duty cycle is based on the idea that the expected energy consumption of a sensor node is proportional to the total awake time, $\mathrm{t}_{1}$, of the node because the radio idle listening power is same as the transmission and reception power in WSNs. Hence a constant power $\mathrm{P}$ is assumed for idle listening, reception and transmission. 


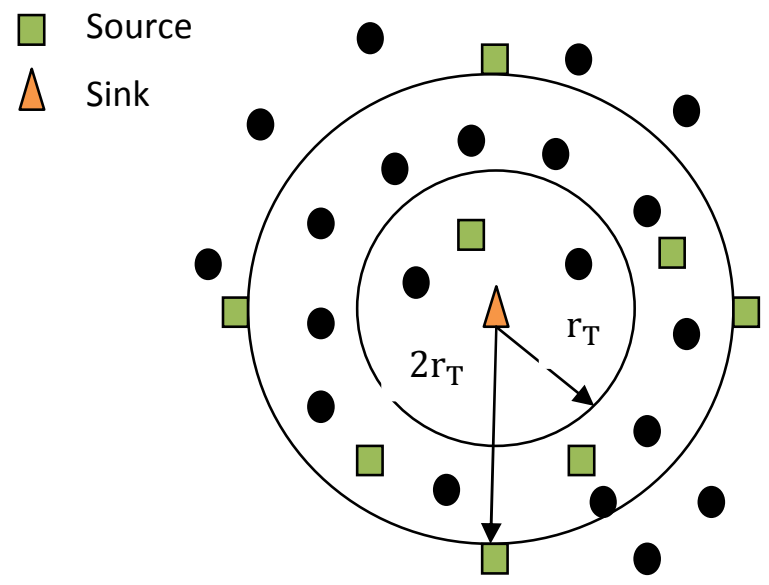

Figure 1. Sample Network Topology

Assuming a uniform packet generation rate, the average traffic rate of a node follows the

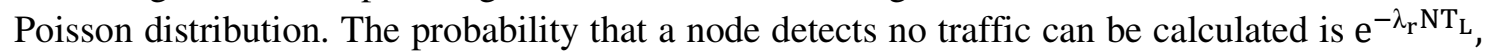
where $T_{L}$ its listen period at each cycle is and $\lambda_{r} N$ is the average packet arrival rate within its transmission range. Thus, the probability that a node detects any ongoing traffic is $\mathrm{p}_{0}=1-$ $\mathrm{e}^{-\lambda_{\mathrm{r}} \mathrm{NT}_{\mathrm{L}}}, \mathrm{p}_{0} \xi$ is the probability of a node detecting ongoing traffic and residing in the relay region of that traffic. When a node has a packet to send, it sends an RTS packet and keeps retransmitting the RTS packet until receiving a CTS packet as shown in Figure 2. The expected number of RTS transmissions needed before the first successful RTS/CTS handshake is

$$
\sum_{\mathrm{i}=1}^{\infty} \mathrm{i}\left(1-\mathrm{p}_{1}\right)^{\mathrm{i}} \mathrm{p}_{1}=\frac{1-\mathrm{p}_{1}}{\mathrm{p}_{1}}=\left(\mathrm{e}^{\xi \mathrm{dN}}-1\right)^{-1}
$$

where, $p_{1}=1-\mathrm{e}^{-\xi \mathrm{dN}}$ is the probability that at least once node replies to the RTS packet. The expected time needed before the first successful RTS/CTS handshake, $t_{\mathrm{H}}$, is then

$$
\mathrm{t}_{\mathrm{H}}=\left(\mathrm{e}^{\xi \mathrm{dN}}-1\right)^{-1}\left(\mathrm{~T}_{\mathrm{RTS}}+\mathrm{N}_{\mathrm{p}} \mathrm{N}_{\mathrm{r}} \mathrm{T}_{\mathrm{CTS}}\right)
$$

where, $\mathrm{T}_{\mathrm{RTS}}$ and $\mathrm{T}_{\mathrm{CTS}}$ are the transmission delays for RTS and CTS packets, respectively.

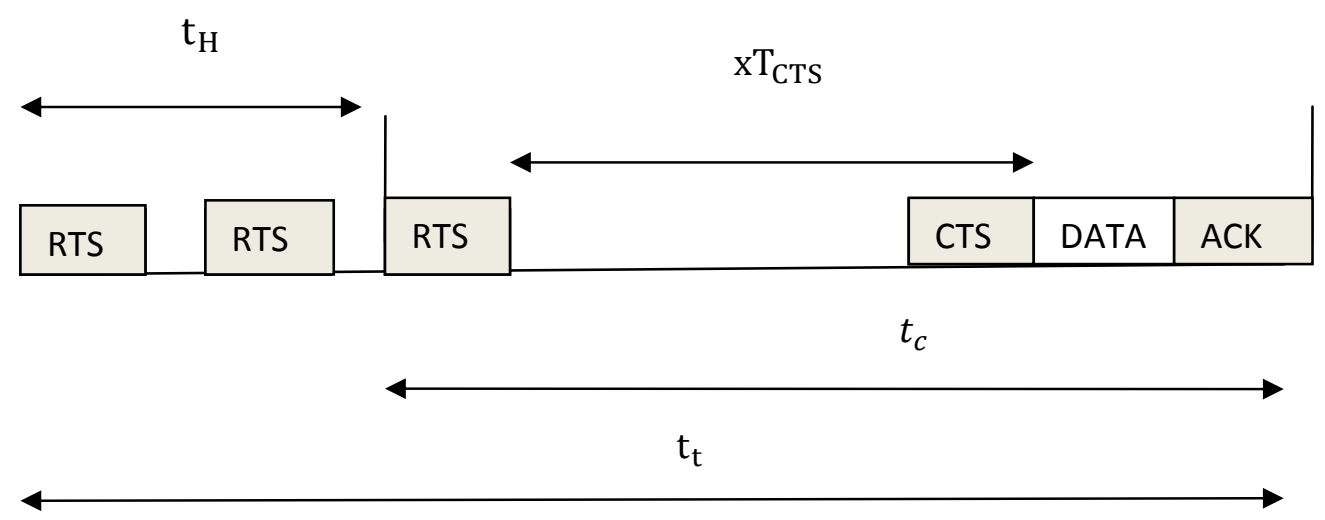

Figure 2. Representation of packet exchange durations 
Here, a constant power $\mathrm{P}$ is assumed for idle listening, reception and transmission. The expected total time for the complete RTS, CTS, DATA, and ACK packet communication is given by

$$
\mathrm{t}_{\mathrm{c}}=\mathrm{t}_{\mathrm{RTS}}+\mathrm{xt}_{\mathrm{CTS}}+\mathrm{t}_{\mathrm{DATA}}+\mathrm{t}_{\mathrm{ACK}}
$$

The expected energy consumption $\overline{\mathrm{P}}$ is defined as:

$$
\overline{\mathrm{P}}=\mathrm{P}\left\{\mathrm{d}+\lambda_{\mathrm{r}}\left[\left(\mathrm{e}^{\xi \mathrm{dN}}-1\right)^{-1} \mathrm{~N}_{\mathrm{p}} \mathrm{N}_{\mathrm{r}} \mathrm{t}_{\mathrm{CTL}}+2 \mathrm{t}_{\mathrm{DATA}}\right]\right\}
$$

where, $\mathrm{P}$ is the constant power, $\mathrm{d}$ is the duty cycle, $\lambda_{\mathrm{r}}$ is the average traffic rate of a node at distance $r, \xi$ is the ratio of the relay region, $\mathrm{N}$ denote the average number of nodes within a node's transmission range, $\mathrm{t}_{\mathrm{RTS}} \cong \mathrm{t}_{\mathrm{CTS}} \cong \mathrm{t}_{\mathrm{ACK}}=\mathrm{t}_{\mathrm{CTL}}$ and it is the total expected time for a complete RTS, CTS, DATA and ACK packet communication. The values used in calculation are listed in Table 3.

Table 3. Parameters used for calculation

\begin{tabular}{|c|c|c|}
\hline Notation & Parameter & Values \\
\hline Power & $\mathrm{P}$ & $40 \mathrm{E}-6$ \\
\hline Average traffic rate of the node & $\lambda_{\mathrm{r}}$ & 0.1 \\
\hline Priority Regions & $\mathrm{N}_{\mathrm{p}}$ & 4 \\
\hline CTS contention slots & $\mathrm{N}_{\mathrm{r}}$ & 4 \\
\hline Ratio of the relay region & $\xi$ & 0.4 \\
\hline Total expected time for transmission & $\mathrm{t}_{\mathrm{CTL}}$ & $1 * \exp (-6)$ \\
\hline Expected time for transmission of data & $\mathrm{t}_{\text {data }}$ & 1.1 \\
\hline
\end{tabular}

\section{RESULTS AND DISCUSSION}

The main objective of this simulation study was to evaluate the lifetime of the battery sensor nodes and dependency of energy consumption of the nodes on duty cycle. The simulations have been performed using MATLAB 7.13 software.

The node's lifetime is determined by its overall energy consumption. If the lifetime is maximized, then the energy consumption is minimized. The lifetime of the sensor node is inversely proportional to the duty cycle. Figure 3 shows the relation between energy consumption and duty cycle. It is concluded from the simulation results that for duty cycle which is less than $0.01 \%$, the energy consumed by the nodes decreases curvy linearly and for duty cycle beyond $0.01 \%$ the energy consumed by the sensor nodes increases linearly. 
International Journal of Computer Networks \& Communications (IJCNC) Vol.5, No.1, January 2013

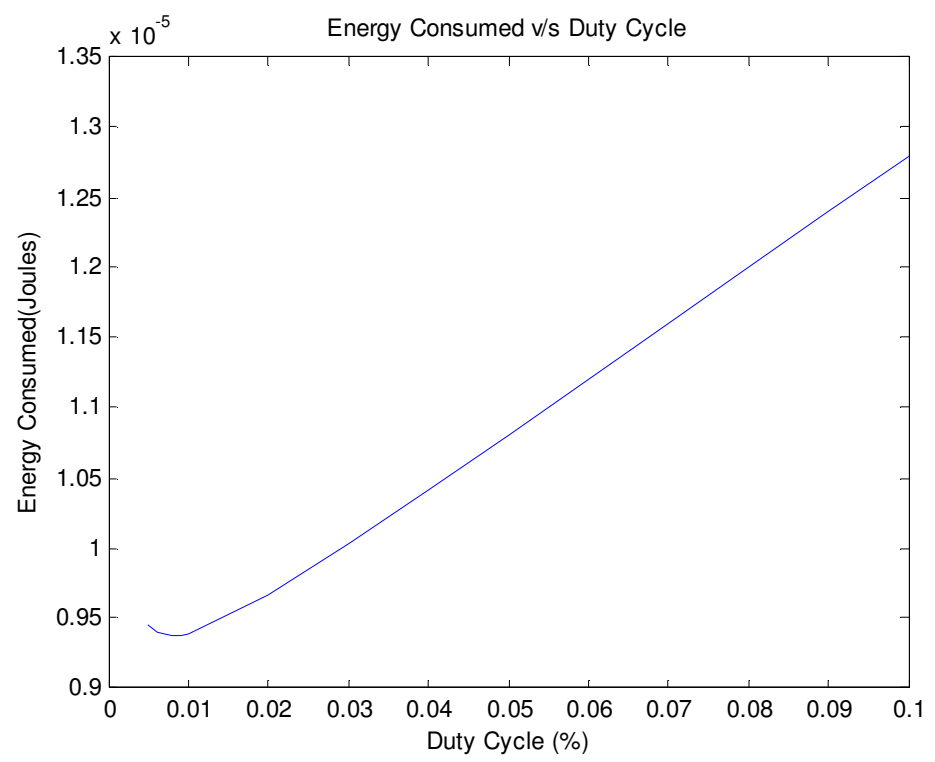

Figure 3. Energy consumed vs Duty cycle

Figure 4 shows the relation between lifetime of the node and the duty cycle (10\%-100\%) and it is concluded from the simulation result that as the duty cycle increases, the lifetime of the node decreases.

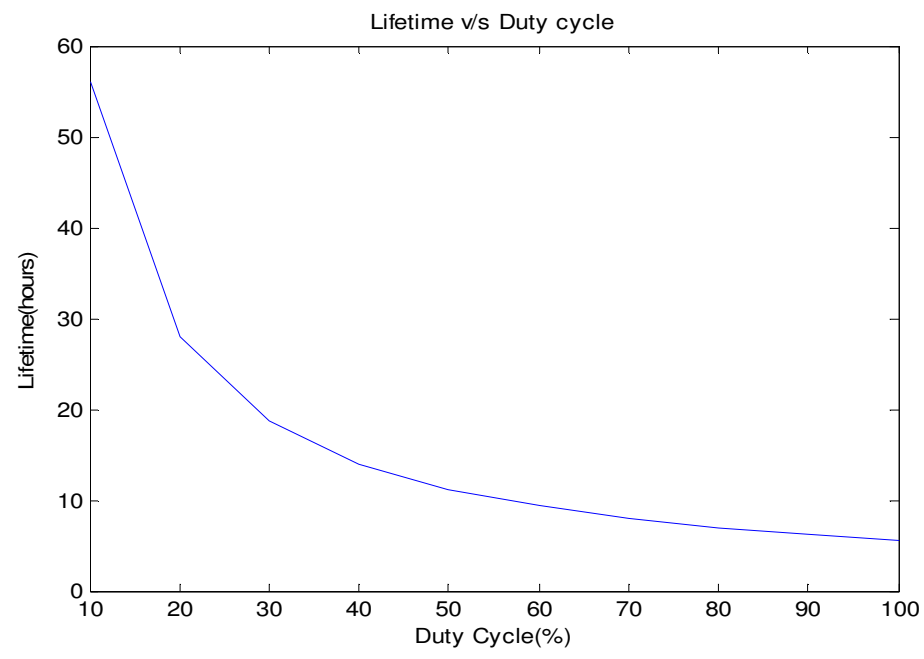

Figure 4. Lifetime vs Duty cycle

As the duty cycle increases the energy consumption of the nodes also increases, so for the optimum power management of the sensor nodes the duty cycle must be reduced. Figure 5(a) shows that for denser network, if the duty cycle is less than $0.01 \%$, energy consumption decreases. For other networks with lower density, same is true for duty cycle value of less than $0.02 \%$. Then the energy consumption increases linearly. It is also evident from the Figure that minimum energy consumption is also achievable even for a denser network. In Figures 5(b)$5(\mathrm{e})$, as the duty cycle increases beyond $0.1 \%$ the energy consumption by the nodes become 
International Journal of Computer Networks \& Communications (IJCNC) Vol.5, No.1, January 2013

congruent even if the traffic rate and the density of node increases. Thus, based on the observations, the optimum value for the duty cycle can be chosen.

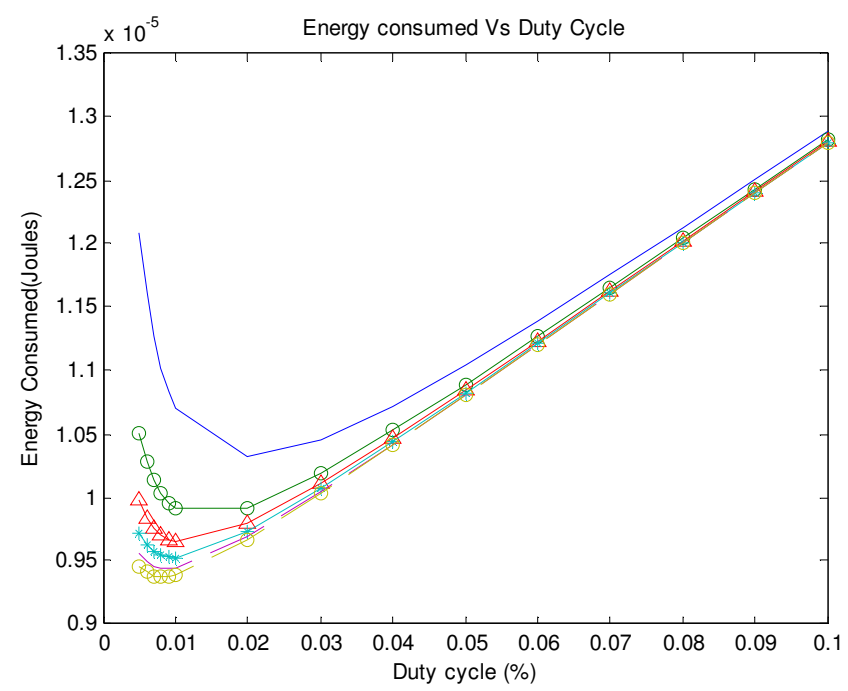

(a)

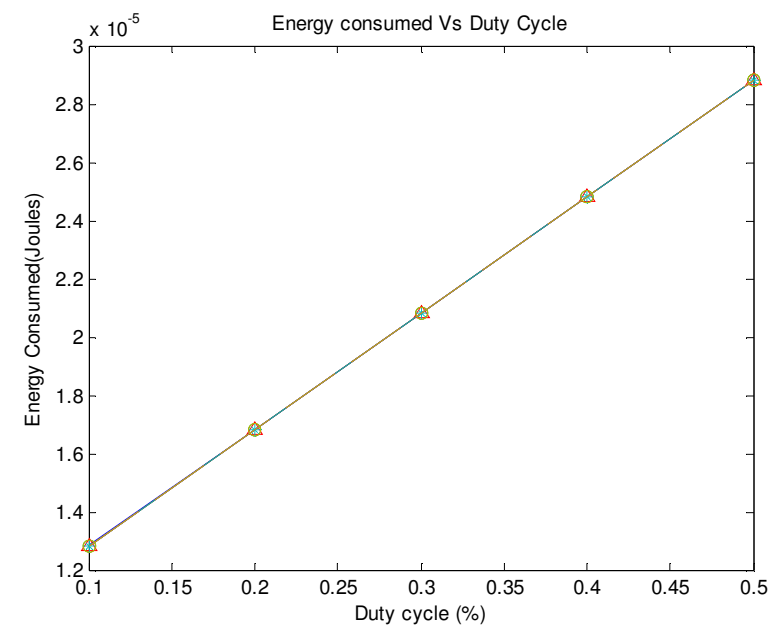

(b) 
International Journal of Computer Networks \& Communications (IJCNC) Vol.5, No.1, January 2013

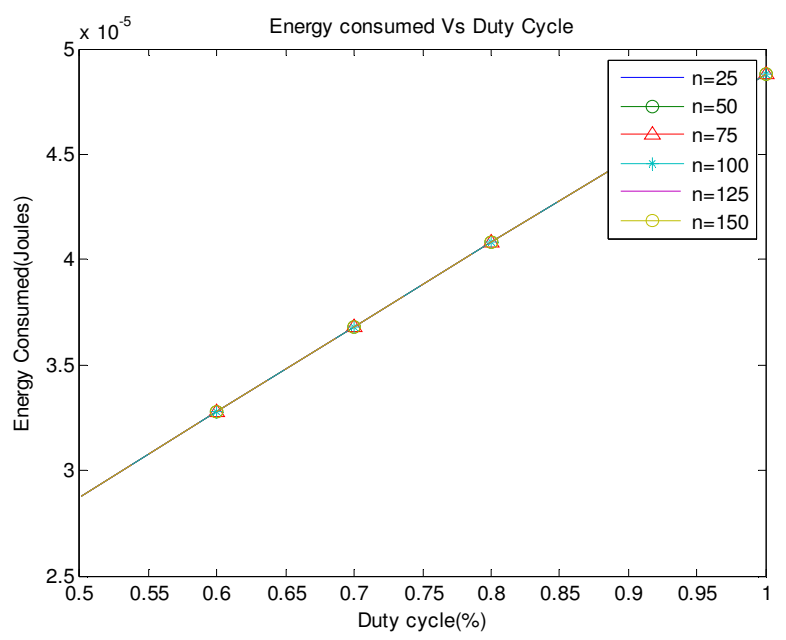

(c)

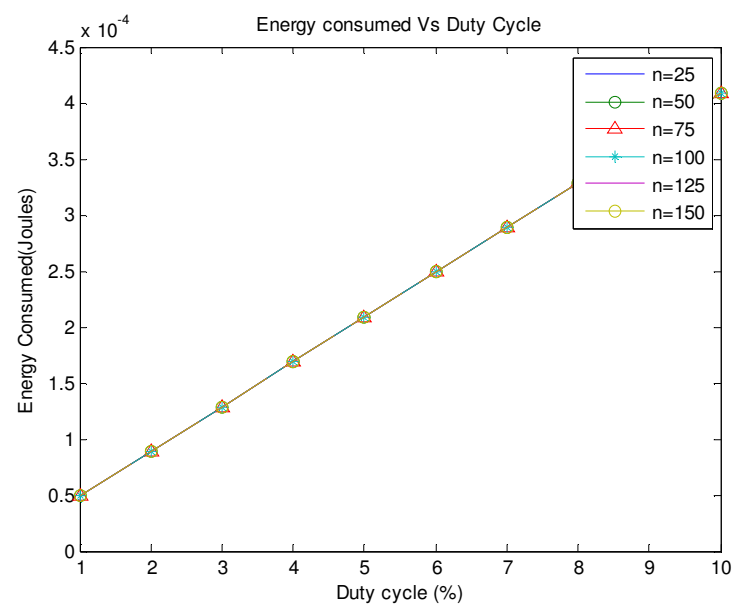

(d)

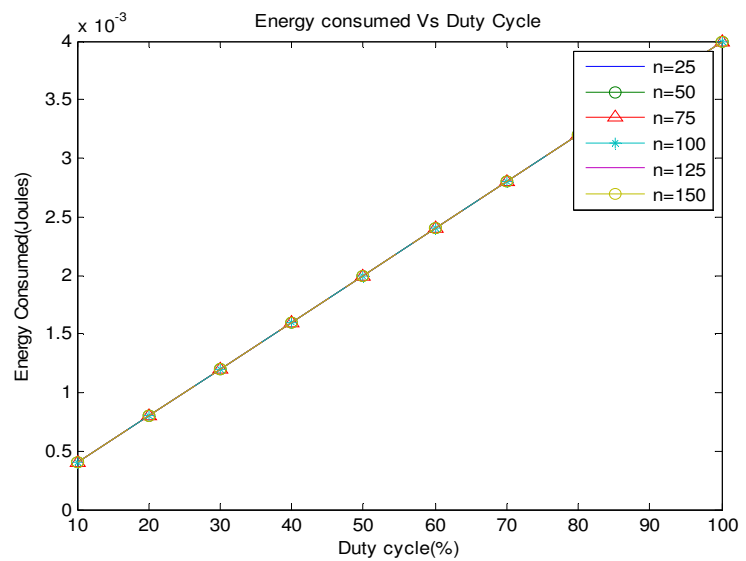

(e) 
International Journal of Computer Networks \& Communications (IJCNC) Vol.5, No.1, January 2013

Figure 5. Energy consumed vs duty cycle for (a) $d=0.01 \%-0.1 \%$, (b) $d=0.1 \%-0.5 \%$, (c) $d=$ $0.5 \%-1 \%$,

(d) $d=1 \%-10 \%,(e) d=10 \%-100 \%$

The relation between number of nodes and energy consumption is estimated $\&$ shown in Figure 6 . The energy consumed by the nodes is directly proportional to the number of nodes. It is seen from the result that with the increase in number of nodes energy consumption of the nodes increases.

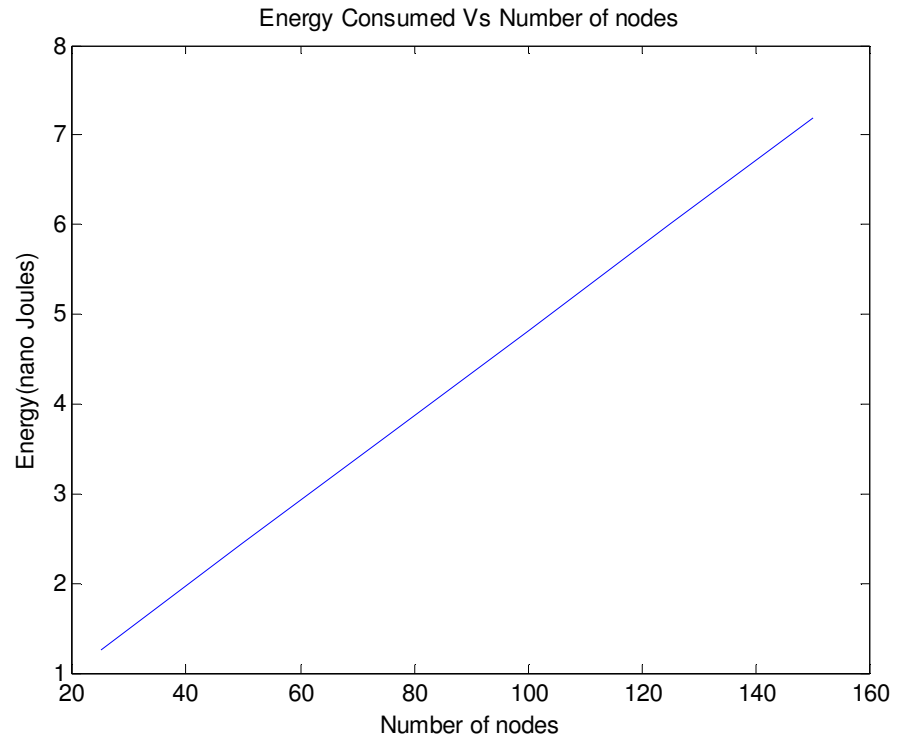

Figure 6. Energy Consumed vs Number of nodes

In Figure 7 it is shown that as we increase the number of the nodes the lifetime of the battery decreases, here CC1000 transceiver is considered and the capacity of the battery is taken as 2500mAh [12]. 
International Journal of Computer Networks \& Communications (IJCNC) Vol.5, No.1, January 2013

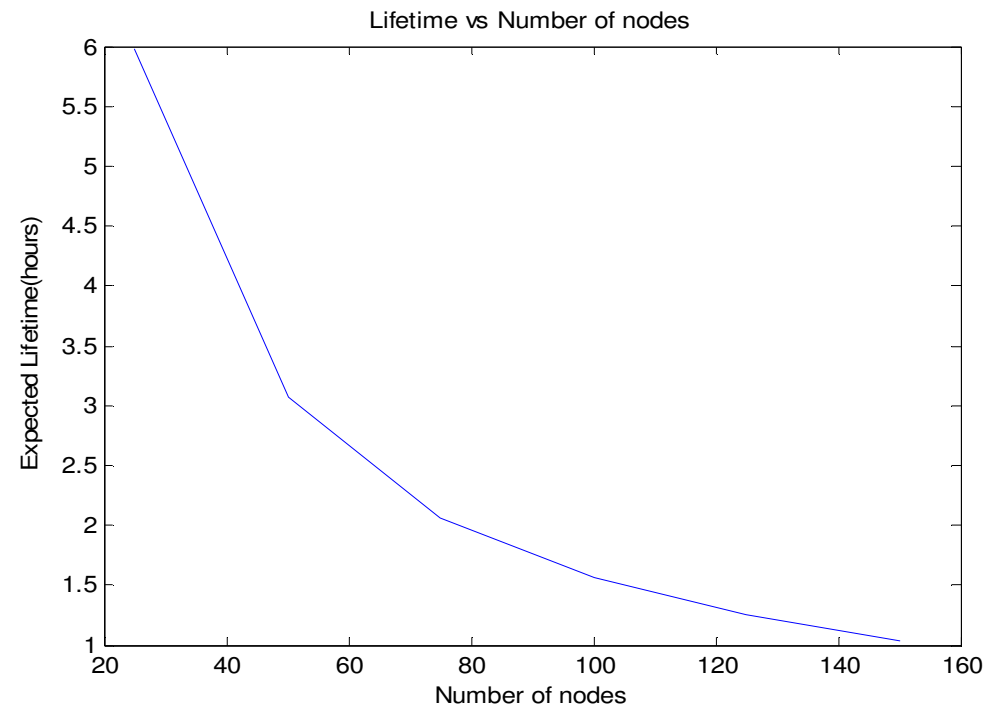

Figure 7. Lifetime vs Number of nodes

\section{Comparison With A Standard Model}

In this section, a comparison between standard model [14] and the proposed model is done. STEM-B is chosen as the standard model.

The total average energy consumption in STEM can be calculated as

$$
\varphi_{\mathrm{s}}=\frac{\mathrm{E}_{\mathrm{tot}}}{\mathrm{P} * \mathrm{t}}
$$

The total average energy consumed during a long time interval of duration $t$, can be expressed as follows:

$$
\mathrm{E}_{\text {tot }}=\mathrm{N}_{\mathrm{T}} \mathrm{E}_{\mathrm{T}}+\mathrm{N}_{\mathrm{l}} \mathrm{E}_{\mathrm{l}}+\mathrm{T}_{\mathrm{s}} \mathrm{P}_{\mathrm{S}}
$$

Where, $\mathrm{N}_{\mathrm{T}}$ and $\mathrm{N}_{\mathrm{l}}$ are the average number of times (during $\mathrm{t}$ ) the node transmits a packet and wakes up to listen respectively, while $\mathrm{E}_{\mathrm{T}}, \mathrm{E}_{\mathrm{l}}$ are the average amount of energy consumed in transmission and listening respectively, $\mathrm{T}_{\mathrm{s}}$ is the total amount of time the two radios remain off, $\mathrm{P}_{\mathrm{S}}$ is the power consumed when both radios are off.

The parameters used are given below:

$\lambda=0.4, \mathrm{P}=40^{*}\left(10^{\wedge}-4\right), \mathrm{t}_{\mathrm{T}}=1.5^{*}\left(10^{\wedge}-6\right), \mathrm{t}=1.1, \mathrm{~N}=150, \mathrm{P}_{S}=400^{*}\left(10^{\wedge}-8\right)$.

where, $\lambda$ is the packet arrival rate at each node, $\mathrm{P}$ is the power consumed by an active radio regardless of its being in transmit, receive or listen mode, $t_{T}$ is the total time when the transmitting node radio is on, $\mathrm{t}$ is the time interval of long duration, $\mathrm{N}$ is the number of nodes, $\mathrm{P}_{S}$ is the power consumed when both radios are off. 


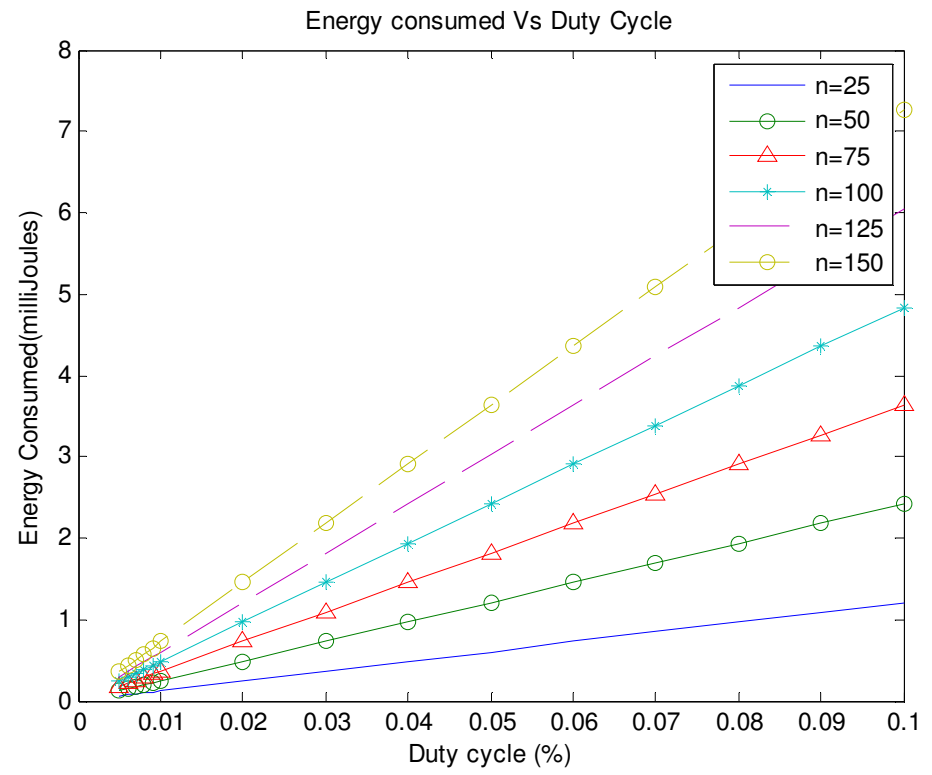

Figure 8. Energy Consumption vs Duty cycle for STEM

Figure 8 shows the variation of energy consumption with duty cycle for different values of number of nodes. The simulation results show that energy consumption increases with duty cycle linearly. It is also evident from the figure that denser is the network, higher is the energy consumption while Figure 5(a) - 5(e) show that for denser network, if the duty cycle is less than $0.01 \%$, energy consumption decreases. For other networks with lower density, same is true for duty cycle value which is less than $0.02 \%$. Then the energy consumption increases linearly. From the study it is clear that energy consumption is lower in our proposed model. As the duty cycle increases beyond $0.1 \%$ the energy consumption by the nodes become congruent even if the traffic rate and the density of node increase. The simulation result shows that the proposed model performed significantly better than existing model.

\section{Conclusions}

In this paper, the lifetime of the node based on overall energy consumption and effect of duty cycle on expected energy consumption are discussed and evaluated. Simulation results show that for denser network, if the duty cycle is less than $0.01 \%$, energy consumption decreases. For other networks same is true for duty cycle value of less than $0.02 \%$. Otherwise, energy consumption increases with duty cycle. This study will, therefore, help in assigning a proper duty cycle value for WSNs based on node density. The proposed model was compared with an existing model (STEM) and performs significantly better for sufficient node density. Scope for future research includes a more detailed analysis, comparison with other proposed schemes and optimization of the parameters. 
International Journal of Computer Networks \& Communications (IJCNC) Vol.5, No.1, January 2013

\section{REFERENCES}

[1] Jamal N.Al-Karaki and Ahmed E. Kamal, "Routing techniques in wireless sensor networks: a survey", wireless communications, IEEE, vol. 11, pp. 6-28, Dec. 2004.

[2] Y. A. Malkani, A. Keerio, J. A. Mahar, G. A. Memon and H. Keeriom, (2012) " Localization, Routing and Data Gathering in Wireless Sensor Networks (WSNs)", Sindh Univ. Res. Jour. (Sci. Ser.), Vol. 44, pp. 15-22.

[3] Tokuya Inagaki and Susumu Ishihara, "HGAF: A power saving scheme for wireless sensor network", Journal of Information Processing, vol. 17, pp. 255-266, Oct. 2009.

[4] Fotis Kerasiotis, Aggeliki Prayati, Christos Antonopoulos, George Papadopoulos, (2010) "Battery Lifetime Prediction Model for a WSN Platform", pp. 525 - 530.

[5] Chulsung Park, Kanishka Lahiri and Anand Raghunathan, (2005) "Battery Discharge Characteristics of Wireless Sensor Nodes", An Experimental Analysis", IEEE SECON 2005, pp. 430 - 440.

[6] E. Y. A. Lin, J. M. Rabaey, and A. Wolisz, "Power-efficient Rendez-vous schemes for dense wireless sensor networks," Proceedings of the IEEE International Conference on Communications, pp. 3769-3776, June 2004.

[7] Honghai Zhang and Jennifer C. Hou, Maximizing -Lifetime for Wireless Sensor Networks, IJSNet 1(1/2), 2006, pp. 64-71.

[8] MS Pawar, JA Manore, MM Kuber, 'Life Time Prediction of Battery Operated Node for Energy Efficient WSN Applications', IJCST Vol. 2, Iss ue 4, Oct . - Dec. 2011.

[9] Yuqun Zhang, Chen-Hsiang Feng, Ilker Demirkol, Wendi Rabiner Heinzelman: Energy-Efficient Duty Cycle Assignment for Receiver-Based Convergecast in Wireless Sensor Networks, pp: 1-5.

[10] Muralidhar Medidi, Yuanyuan Zhou, 'Extending Lifetime with Differential Duty Cycles in Wireless Sensor Networks', IEEE Communications Society subject publication, May 7, 2009.

[11] Francesco Zorzi, Milica Stojanovic and Michele Zorzi, 'On the Effects of Node Density and Duty Cycle on Energy Efficiency in Underwater Networks’, Conference Europe, 2010.

[12] Joseph Polastre, Jason Hill, David Culler, 'Versatile Low Power Media Access for Wireless Sensor Networks', November 3-5, 2004.

[13] M. Zorzi and R. R. Rao, "Geographic random forwarding (GeRaF) for ad hoc and sensor networks: Energy and latency performance," IEEE Transactions on Mobile Computing, vol. 2, no. 4, pp. 349$365,2003$.

[14] Curt Schurgers, Vlasios Tsiatsis, Saurabh Ganeriwal, Mani Srivastava, "Optimizing sensor networks in the energy-latency-density design space," IEEE Trans. on Mobile Computing, vol. 1, Jan-Mar 2002, p. 70-80.

\section{Authors}

Jyoti Saraswat was born in India on November 26, 1987. She received her B.Tech degree in Electronics and Communication Engineering from Modi Institute of Engineering and Technology, Rajasthan University, India in 2010 and currently is a M. Tech (Signal Processing) student in Mody Institute of Technology and Science (Deemed University), Rajasthan, India. Her research interest lies in Wireless Sensor Networks.

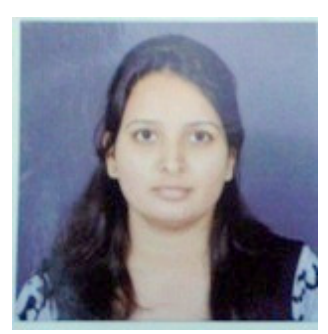


International Journal of Computer Networks \& Communications (IJCNC) Vol.5, No.1, January 2013

Dr. Partha Pratim Bhattacharya was born in India on January 3, 1971. He has 16 years of experience in teaching and research. He served many reputed educational Institutes in India in various positions. At present he is working as Professor in Department of Electronics and Communication Engineering in the Faculty of Engineering and Technology, Mody Institute of Technology and Science (Deemed University), Rajasthan, India. He worked on Microwave devices and systems and mobile cellular communication systems. He has published 80 papers in refereed journals and conferences. His present research interest includes mobile cellular communication, wireless sensor network and

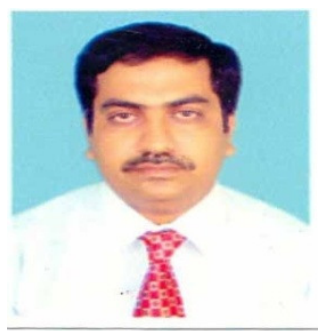
cognitive radio.

Dr. Bhattacharya is a member of The Institution of Electronics and Telecommunication Engineers, India and The Institution of Engineers, India. He is the recipient of Young Scientist Award from International Union of Radio Science in 2005. He is working as the chief editor, editorial board member and reviewer in many reputed journals. 